\title{
A criação de municípios e a formalização de regiões metropolitanas: os desafios da coordenação federativa'
}

\author{
The creation of municipalities and the formalization of metropolitan areas: \\ federal coordination challenges
}

Antônio Sérgio Araújo Fernandes ${ }^{[a]}$, Suely Mara Vaz Guimarães de Araújo[b]

[a] Universidade Federal da Bahia (UFBA), Núcleo de Pós-Graduação em Administração (NPGA), Salvador, BA, Brasil

[b] Universidade de Brasília (UnB), Instituto de Ciência Política (IPOL), Brasília, DF, Brasil

\section{Resumo}

0 trabalho visa analisar a atuação do governo federal em dois temas relacionados à questão federativa: a criação de municípios e a formalização de regiões metropolitanas. A intenção foi compreender a lógica subjacente às decisões do governo federal nesse campo após a promulgação da Constituição. Considera-se que a atuação da União entre esses polos demanda análise detida por suas implicações evidentes em políticas públicas diversas, como habitação, saneamento básico, mobilidade urbana, educação, saúde e outras. Entre os elementos estudados, enfatizam-se as propostas legislativas apresentadas e as mudanças institucionais ocorridas, ou não. Os eventos ocorridos neste pouco mais de um quarto de século, analisados com base no método das narrativas, evidenciam que o governo federal tem demonstrado dificuldade na coordenação desse campo. Não raramente tem havido omissão, a exemplo da desatenção do Executivo federal para as regiões metropolitanas e outras aglomerações urbanas, e, no sentido oposto, imposições do governo central desconsiderando a federação, a exemplo da decisão de não decidir sobre as regras nacionais referentes à criação de novos municípios.

Palavras-chave: Federação. Municipalismo. Regiões metropolitanas.

\section{Abstract}

This work aims to analyze the federal government actions on two topics related to the federative issue: creation of municipalities and formalization of metropolitan areas. The goal was to understand the rationale underlying the federal government decisions in this field after the Constitution promulgation. The Union action between these poles demands analysis by its obvious implications in various public policies such as housing, sanitation, urban mobility, education, health and others. Among the studied elements, we emphasize the legislative proposals and

\footnotetext{
${ }^{1}$ Versões deste texto foram apresentadas no IX Encontro da Associação Brasileira de Ciência Política (ABCP), em Brasília (DF), em 7 de agosto de 2014, e também no IV Encontro Nacional de Administração Pública e Governança (ENAPG) da Associação Nacional de Pesquisa e Pós-Graduação em Administração (ANPAD), em 18 de novembro de 2014, em Belo Horizonte (MG).
}

ASAF é doutor em Ciência Política pela Universidade de São Paulo (USP), e-mail: antoniosaf@ufba.br SMVGA é doutora em Ciência Política pela Universidade de Brasília (UnB), e-mail: suely.araujo@camara.leg.br 
institutional changes, whether it occurred or not. Events occurring in this little more than a quarter century, analyzed in accordance to the narrative method, show that the federal government has shown difficulty to coordinate this field. Omission is not rare, such as lack of attention by the federal executive to metropolitan and other urban areas and, on the other hand, central government levies disregarding the federation, such as the decision not to decide on national rules relating to the creation of new municipalities.

Keywords: Federation. Municipal approach. Metropolitan areas.

\section{Introdução}

0 objetivo do trabalho é analisar a atuação do governo federal em dois temas importantes relacionados à coordenação federativa: (i) a criação de municípios e (ii) a formalização de regiões metropolitanas. A questão central colocada é: qual é a lógica subjacente às decisões do governo federal nesse campo no pós-1988?

Entre os principais temas da governança federativa, estão a incorporação, a fusão e o desmembramento de municípios, bem como a formalização de regiões metropolitanas, aglomerações urbanas e microrregiões, constituídas de municípios limítrofes, para integrar a organização, o planejamento e a execução de funções públicas de interesse comum. Considera-se que a dinâmica desses temas após a Constituição de 1988 traz questionamentos sobre as decisões do governo central quanto aos polos coordenação central versus autonomia dos Estados e municípios. A atuação da União entre esses polos demanda análise detida, por suas implicações evidentes em políticas públicas diversas, como habitação, saneamento básico, mobilidade urbana, educação, saúde e outras.

De 1988 a 1996, ocorreu a criação de cerca de 1.000 municípios no Brasil, chegando-se a mais de 5.500 até a promulgação da Emenda Constitucional n. 15 (Brasil, 1996), que passou a exigir legislação de âmbito nacional, disciplinando o tema e dispondo sobre os Estudos de Viabilidade Municipal (EVM). A opção do Executivo federal tem sido impedir a aprovação de lei com esse conteúdo, posição que se consolidou com o veto total da Presidenta da República ao Projeto de Lei (Complementar) do Senado n. 104/2014. Na prática, na ausência de legislação regulamentadora, os municípios somente podem ser criados, hoje, mediante decisão judicial.

No que se refere à criação de regiões metropolitanas, a escolha da Constituição ( $§ 3^{\circ}$ do art. 25) deixa a cargo dos estados essa prerrogativa, que se concretiza mediante a aprovação de lei complementar estadual (Brasil, 2015c). Na Assembleia Nacional Constituinte, entre um conjunto de propostas, que incluía a possibilidade de um governo metropolitano com características próximas a um quarto nível da federação, prevaleceu-se a tese de descentralização para os estados do poder decisório nesse campo (Fernandes, 2009), rompendo a institucionalidade metropolitana imposta pelo governo central (Souza, 2003). Com isso, em princípio, também se evitaria que realidades sociais, econômicas, geográficas e culturais distintas fossem tratadas sem o respeito a suas particularidades, como acontecia quando as regiões metropolitanas eram instituídas por lei complementar federal.

A partir da segunda metade dos anos de 1990, observou-se a criação de grande número de regiões metropolitanas pelos governos estaduais. Tem-se hoje mais de 60 regiões metropolitanas no país, com características muito variadas e sem observância de critérios consistentes quanto à população, ao grau de urbanização e à centralidade regional que deveriam caracterizar essas unidades regionais.

A União, por seu turno, não tem trabalhado diretamente com a gestão metropolitana no Ministério das Cidades. 0 tema aparece incluso pontualmente em algumas políticas setoriais, mas não é objeto de abordagem interdisciplinar pelo Executivo. Há também escolhas tecnicamente frágeis, como a instituição pela União de três Regiões Integradas de Desenvolvimento (Rides) com características essencialmente urbanas, a maior delas a Ride do Distrito Federal (DF) e Entorno, que, em sua essência, é uma região metropolitana interestadual.

No Congresso Nacional, o consenso parece estar na necessidade de se estabelecerem parâmetros para a criação de regiões metropolitanas e de outras aglomerações urbanas pelos estados. Se no curso da tramitação da Lei n. 10.257 - Estatuto da Cidade (Brasil, 2001) -, a decisão foi não decidir sobre esse assunto e mantê-lo apenas na esfera estadual, essa posição foi reorientada e levou à aprovação do Projeto 
de Lei (PL) n. 3.460/20042, sancionado na forma da Lei n. 13.089 - Estatuto da Metrópole (Brasil, 2015a).

Para desenvolver o estudo, empreendeu-se uma análise histórica da atuação do governo federal nos dois temas já referidos, utilizando o método das narrativas. Enfatizam-se as propostas legislativas apresentadas e as mudanças institucionais ocorridas, ou não, a partir das decisões governamentais.

Este trabalho está estruturado em seis seções, contando com esta introdução. A seção 2 expõe o método utilizado. A seção 3 aborda a criação de municípios no Brasil, observando a evolução após 1988 e o os debates no Congresso Nacional. A seção 4 trata da formalização das regiões metropolitanas, buscando observar sua evolução e os esforços de regulação nesse sentido. 0 texto ainda traz a seção 5 , com considerações finais.

\section{Método das narrativas}

O método das narrativas é um método de análise histórica que propõe aproximar-se da realidade social em suas características processuais e vinculadas à ação, o que possibilita organizar o fluxo de eventos observados em função de um sentido global atribuído ao fenômeno em estudo, prestando-se a apreender a realidade social como processo (Barzelay \& Cortazar-Velarde, 2004; Fernandes, 2010).

Esse método baseia-se em eventos, e não em variáveis - centra-se na explicação contextualizada e não abstraída das particularidades do objeto de estudo. A explicação a respeito do fenômeno pesquisado é obtida a partir da construção de uma narrativa lógica, por meio da qual as relações entre eventos e decisões são explicadas: "[...] o método narrativo explica o fluxo de ações recorrendo ao contexto singular no qual elas ocorreram [...]" (Barzelay \& Cortazar-Velarde, 2004, p. 20-21).

0 resultado da aplicação do método é o relato, definido como "[...] uma forma de representar uma experiência que conecta os acontecimentos em função do efeito que exercem sobre a experiência global [...]" (Barzelay \& Cortazar-Velarde, 2004, p. 21). 0 relato é composto por dois elementos básicos: os "eventos" e a "trama”. Barzelay \& Cortazar-Velarde (2004, p. 22-23)

\footnotetext{
${ }^{2}$ Número na Câmara dos Deputados, casa de origem. No Senado, ver Projeto de Lei da Câmara (PLC) n. 5/2014.
}

apontam os eventos como elementos básicos na análise por meio da narrativa e o definem como "[...] conjuntos de ações ou ocorrências organizadas em função de seu significado no âmbito de uma experiência considerada em sua totalidade". Os eventos são delineados, descritos e analisados a partir do resultado ou "estado final" ao qual conduzem os acontecimentos ou da trajetória que esses acontecimentos seguem (Barzelay \& Cortazar-Velarde, 2004, p. 23).

Seguindo o procedimento metodológico apresentado por Barzelay \& Cortazar-Velarde (2004), em relação à criação de municípios, assume-se, neste trabalho o quadro anterior à nova Constituição e a própria Carta de 1988 como configuração de um conjunto de eventos prévios. A aprovação da Emenda Constitucional n. 15/1996, impulsionada pelo grande número de municípios no país, é evento central, do qual derivam, na condição de eventos posteriores, quatro processos legislativos que pretendem regulamentar o $\S 4^{\circ}$ o do art. 18 da Constituição, mas que levaram a um mesmo resultado: o veto integral pela Presidência da República. No tema regiões metropolitanas, o quadro anterior a 1988 reúne o conjunto de eventos prévios, com a estadualização das decisões sobre o tema advinda da Constituição. A explosão do número de regiões metropolitanas é evento central, do qual decorre a aprovação do Estatuto da Metrópole como evento posterior. 0 processo e a aprovação do Estatuto da Cidade em 2001 colocam-se como um conjunto de eventos relacionados.

\section{Criação de municípios no Brasil}

\section{Da explosão ao arrefecimento das emancipações municipais}

Um dos maiores problemas enfrentados na federação brasileira é a autonomia municipal devido à baixa capacidade fiscal, financeira e institucional dos governos locais para absorver e dar conta de todas as suas funções constitucionais, inclusive a política urbana. Essa assertiva foi debatida na literatura sobre federalismo no Brasil por vários autores, entre eles Abrucio (2005), Almeida (2005), Arretche (2000) e Souza (1996).

A baixa capacidade financeira dos municípios brasileiros ocorre mesmo com a partilha de impostos federais e estaduais, estabelecida pela Constituição, 
além das transferências de recursos vinculadas a políticas sociais, sobretudo nas áreas de saúde e de educação. Acerca da municipalização das políticas sociais, é consenso que se impõe coordenação e colaboração entre as esferas de governo, algo que ainda não ocorre como deveria no caso da descentralização brasileira. A descentralização das políticas sociais permanece como processo ainda inconcluso no país (Almeida, 2005), não obstante os avanços recentes em termos de coordenação federal para a redução das iniquidades nesse campo (Arretche, 2012). Os municípios acumulam uma série de problemas relacionados à execução de suas atribuições constitucionais de políticas públicas, no que se refere tanto ao provimento quanto à qualidade dos serviços.

Além da fraca coordenação federativa, que dificulta a municipalização das políticas sociais, a baixa capacidade institucional, fiscal e financeira dos municípios brasileiros, sobretudo nos de menor população, torna a tarefa de municipalização de políticas públicas como algo a ser ajustado. É isso que se verá ao longo da primeira década do século XXI, com o incremento do número dos consórcios e, mais recentemente, com o retorno do discurso metropolitano, que enfraquecera a partir de 1988. Em outras palavras, o "municipalismo autárquico" da Constituição de 1988 (Abrucio, 2005), ainda que lograsse conquistas consideradas importantes para os governos locais, parece ter apresentado características de um jogo de soma zero, se analisado o conjunto do país, ou pelo menos ter resultados questionáveis, quando se pondera a escala nacional.

Há desigualdade de autonomia financeira e fiscal entre municípios brasileiros e isso também se reproduz na maior parte das regiões metropolitanas em relação ao seu município-sede (núcleo) e os demais municípios. 0 que se observa quanto à situação fiscal e financeira dos municípios brasileiros é que a maioria dos pequenos municípios possui rigidez financeira na despesa, sobretudo pelas despesas com pessoal e vinculações de recursos em educação e saúde, algo que dificulta fortemente os investimentos municipais. Além disso, os municípios de menor população possuem fraca receita tributária e dependem fortemente de recursos de transferências intergovernamentais, notadamente as federais, sejam as constitucionalmente estabelecidas ou as voluntárias.

Segundo o Censo 2010 (IBGE, 2011), o Brasil possuía 5.565 municípios com uma população de
190.732.694 milhões de habitantes ${ }^{3}$. Santos (2013) mostra que $45,9 \%$ dos municípios têm menos de 10 mil habitantes, $24,9 \%$ estão na faixa entre 10 e 20 mil habitantes, $24,4 \%$, na faixa entre 20 e 100 mil. Os municípios grandes, assim considerados os que possuem mais de 100 mil habitantes, são apenas 4,4\% do total, concentrando 53,9\% da população.

A União responde pela maior parte da arrecadação no país. O Imposto sobre Circulação de Mercadorias e Serviços de Transporte e Comunicação (ICMS) é o tributo com maior volume de arrecadação no país, mas é concentrado nos estados de maior atividade econômica. A carga tributária da União correspondia a 20,53\% em 1990 do Produto Interno Bruto (PIB) e a 23,46\% em 2010; a dos Estados representava 9,02\% do PIB em 1990 e 8,47\% em 2010; a dos municípios era de apenas 0,95\% do PIB em 1990 e 1,63\% em 2010 (Monteiro, 2013). Em um quadro como esse, fica patente a importância das transferências federativas, obrigatórias ou voluntárias, notadamente as que envolvem recursos federais.

O Fundo de Participação dos Municípios (FPM), o principal instrumento de partilha para os municípios, consolidado no art. 159 da Constituição Federal, insere mecanismos redistributivos, focados historicamente na relação capital/interior. Como estabelecido pela Lei n. 5.172 (Brasil, 1966), que dispõe sobre o Código Tributário Nacional (CTN), do valor total destinado ao FPM, 10\% são distribuídos entre as capitais dos estados e o restante para os demais municípios. No cálculo referente às capitais, ponderam-se fator representativo da população do município e fator representativo do inverso da renda do respectivo estado. Nos demais municípios, o cálculo é feito por coeficiente que se baseia no número de habitantes ${ }^{4}$.

Além das transferências tributárias propriamente ditas, existem as vinculações constitucionais para as áreas de saúde e de educação, que se relacionam em

\footnotetext{
${ }^{3}$ Atualmente, há 5.570 municípios no país. Foram criados cinco novos municípios em 2013, como se explicará mais adiante.

${ }^{4} 0$ total de recursos do FPM é segmentado em três partes: 10\% são entregues aos municípios, que são capitais de estados; $86,4 \%$ aos municípios não capitais; $3,6 \%$ constituem uma reserva para suplementar a participação dos municípios mais populosos do interior com mais de 156.216 habitantes, de acordo com o Decreto-Lei n. 1.881 (Brasil, 1981). Para calcular o FPM, são utilizados coeficientes de participação divulgados anualmente pelo Tribunal de Contas da União (TCU).
} 
parte a repasses federais e estaduais aos municípios. Nesse âmbito, devem ser citados o extinto Fundo de Manutenção e Desenvolvimento do Ensino Fundamental e Valorização do Magistério (FUNDEF), o Fundo de Manutenção e Desenvolvimento da Educação Básica e Valorização dos Profissionais da Educação (FUNDEB) e o Fundo Nacional de Saúde (FNS).

No quadro institucional da Constituição anterior (Brasil, 1967), a criação de municípios condicionava-se a requisitos mínimos de população, uniformes para todo o país: população estimada superior a $10 \mathrm{mil}$ habitantes ou não inferior a 5 milésimos da população existente no estado; eleitorado não inferior a $10 \%$ da população; centro urbano já constituído, com o mínimo de 200 casas; arrecadação mínima de 5 milésimos da receita estadual de impostos ${ }^{5}$. Atendidos a esses requisitos, a assembleia legislativa do respectivo Estado podia determinar a realização de plebiscito e, havendo resultado favorável, editar a lei de criação do novo município.

Com o texto original do $\S 4^{\circ}$ do art. 18 da Constituição de 1988, deixou de existir padrão mínimo imposto pelo poder central e delegaram-se os requisitos a lei complementar estadual (Brasil, 1988) ${ }^{6}$. Esse tipo de descentralização aconteceu também em relação à decisão de se instituírem regiões metropolitanas e, no quadro político da época, conectava-se diretamente com o ideário de democratização do país. A própria consagração dos municípios como entes com plena autonomia e como titulares de políticas públicas relevantes está conectada com tal ideário (Souza, 1996).

Com a liberdade decisória conferida aos estados nesse sentido, e os estímulos advindos das transferências obrigatórias de recursos e mesmo da expectativa de transferências voluntárias, impulsionou-se um boom de emancipações municipais. "As leis complementares estaduais produzidas para regular o dispositivo constitucional citado, via de regra, estabeleceram requisitos tíbios, o que facilitou os procedimentos de emancipação [...]" (Araújo \& Lorenzetti, 2008,

\footnotetext{
${ }^{5}$ Ver Lei Complementar n. 1/1967.

${ }^{6}$ No texto promulgado em 1988, o § 4o do art. 18 dispunha: "A criação, a incorporação, a fusão e o desmembramento de Municípios preservarão a continuidade e a unidade histórico-cultural do ambiente urbano, far-se-ão por lei estadual, obedecidos os requisitos previstos em lei complementar estadual, e dependerão de consulta prévia, mediante plebiscito, às populações diretamente interessadas." (Brasil, 1988).
}

p. 641). Em grande parte, os novos entes políticos não dispunham de receita própria compatível com as demandas de sua sustentação, tornando-se dependentes de transferências federativas.

Entre a segunda metade dos anos de 1980 até o ano de 2010, foram criados mais de 1.500 municípios (IBGE, 2011). Nesse período, o intervalo de tempo com mais intensidade de emancipações municipais foi a década de 1990, na qual foram criados mais de 1.000 municípios no país, ocorrendo logo em seguida, na primeira década do século XXI, um arrefecimento forçado nesse processo pela interveniência do governo federal, como se explicará a seguir. Na verdade, as criações de novos municípios estão represadas desde 1996.

Entre 1988 e 2000, foram criados 1.438 municípios, sendo que a grande maioria deles, 1.145 (76\%) municípios emancipados, possuía menos de 10 mil habitantes, como mostra a Tabela 1.

Dessa forma, a partir de 1988, os pequenos municípios tiveram incentivos institucionais para buscar sua emancipação por duas razões principais. A primeira diz respeito às regras existentes de transferência de recursos, que tornavam possível os municípios se emanciparem calçados em recursos oriundos de transferências, mesmo sem garantia de tributação local. Essa é uma escolha racional para a municipalidade no curto prazo, dado que existe um trade-off entre receitas próprias e transferências, havendo maior distribuição de recursos para as cidades do interior e a segurança de um mínimo de receita via FPM. A segunda diz respeito ao fato de a Constituição ter remetido as regras de criação de novos municípios integralmente para a esfera estadual.

Cabe dizer que o boom da década de 1990 ocorreu em um contexto em que se verifica conexão eleitoral nas emancipações municipais, a qual partia das lideranças locais com os deputados estaduais e deles com o Executivo estadual, visando a votos dos eleitores do interior do estado. Assim se explicam as leis complementares estaduais com critérios pouco rígidos para a criação de municípios no final dos anos de 1980 e início dos anos de 1990. Esse processo, contudo, estava respaldado pelo discurso que conecta normativamente descentralização política na federação e democratização (Souza, 1996; Lijphart, 2003).

Os pequenos municípios experimentaram uma situação em que poderiam gozar de autonomia política, mesmo com dependência financeira das transferências 
Tabela 1 - Municípios criados entre 1988 e 2000 por tamanho da população

\begin{tabular}{|c|c|c|c|c|c|c|c|c|c|c|}
\hline \multicolumn{2}{|c|}{ Municípios } & \multicolumn{2}{|c|}{ Incremento } & \multicolumn{7}{|c|}{$\begin{array}{l}\text { Municipios criados por tamanho da população } \\
\text { (em mil hab.) }\end{array}$} \\
\hline 1988 & 2000 & Total & $\%$ & & & & & & & Total \\
\hline 4.121 & 5.559 & 1.438 & 35 & 765 & $53 \%$ & 380 & $27 \%$ & 293 & $20 \%$ & 1.438 \\
\hline
\end{tabular}

Fonte: Adaptado de Tomio (2002, p. 64).

e quase nenhuma força de arrecadação tributária. No longo prazo, esse tipo de estímulo mostrar-se-á um jogo de soma zero, como anteriormente referido, pois os governos locais não conseguirão com esse arranjo manter suas funções nas políticas públicas estabelecidas pela própria Constituição Federal.

A Emenda Constitucional n. 15 restringiu fortemente esse movimento de criação acelerada de novos municípios e, em pouco tempo, estagnou o processo das emancipações municipais. 0 texto, incluso na Constituição por essa emenda, atualmente em vigor, dispõe:

Art. 18.

§ 4ํA A criação, a incorporação, a fusão e o desmembramento de Municípios, far-se-ão por lei estadual, dentro do período determinado por lei complementar federal, e dependerão de consulta prévia, mediante plebiscito, às populações dos Municípios envolvidos, após divulgação dos Estudos de Viabilidade Municipal, apresentados e publicados na forma da lei. (Brasil, 1996).

Há previsão, então, de uma lei complementar federal relativa ao período de processamento ${ }^{7}$ de propostas de criação, incorporação, fusão e desmembramento de municípios e de uma lei ordinária disciplinando os EVM. Tem-se consolidado a opção de editar uma lei complementar que trata de todos os aspectos envolvidos nesses processos, inclusive os EVM, provavelmente em razão de essa parecer ser a opção jurídica da Presidência da República (Araújo \& Lorenzetti, 2008).

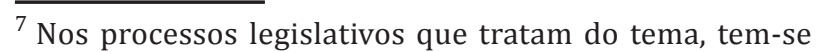
proposto, entre outros pontos, que se proíba a tramitação de procedimentos para criação, incorporação, fusão ou desmembramento de municípios a partir de determinado prazo da data prevista para a realização das eleições municipais.
}

Deve-se notar na redação anterior, ainda, a substituição da expressão "populações diretamente interessadas", que constava na redação anterior, pelas "populações dos Municípios envolvidos", o que implica a inclusão, na consulta plebiscitária, da população do município-mãe (Araújo \& Lorenzetti, 2008). Anteriormente, entendia-se que a consulta deveria ser realizada apenas aos eleitores da área que se estava desmembrando (IBGE, 2011).

A ideia subjacente à Emenda Constitucional n. 15 (Brasil, 1996) foi dificultar a criação de novos municípios e também retomar o poder da União de estabelecer padrões nacionais mínimos para isso, como ocorria no regime da Carta de 1967. Evidencia-se a constatação da necessidade de regras gerais diante da explosão do número de municípios, até mesmo pela previsão das transferências obrigatórias de recursos por parte da União. Nesse evento específico, não parece sobressair opção por moldes políticos centralizadores que tenham relação direta com dependência de trajetória (North, 1993; Pierson, 2004).

Não existe hoje nem lei complementar nem lei ordinária regulamentadora do dispositivo da Constituição anteriormente transcrito, promulgado em 1996. Com isso, leis estaduais criando novos municípios passaram a ser judicializadas. A jurisprudência do Tribunal Superior Eleitoral (TSE) e do Supremo Tribunal Federal (STF) consolidou-se no sentido da inviabilidade de criação de municípios enquanto não editada a lei complementar federal a que se refere o $\S 4^{\mathrm{o}}$ do art. 18 da Constituição Federal.

Em face das disputas judiciais nesse sentido, o Congresso Nacional aprovou a Emenda Constitucional n. 57/2008, inserindo no Ato das Disposições Constitucionais Transitórias (ADCT) o art. 96, que convalida “[...] os atos de criação, fusão, incorporação e desmembramento de municípios, cuja lei tenha sido publicada até 31 de dezembro de 2006, atendidos os 
requisitos estabelecidos na legislação do respectivo Estado à época de sua criação [...]" (Brasil, 2008).

Por decorrência dessa emenda, foram reconhecidos a partir de 1 o de janeiro de 2013 cinco novos municípios no país: Pescaria Brava e Balneário Rincão (SC), Mojuí dos Campos (PA), Pinto Bandeira (RS) e Paraíso das Águas (MS) ${ }^{8}$. Os cinco processos de emancipação encaminhados para sanção presidencial ocorreram com vetos à totalidade das propostas por parte do Executivo. Além disso, a formalização desses cinco municípios envolveu processos no STF (Castro, 2013). Mesmo com a criação desses cinco municípios, parece manter-se uma situação observada ao longo do tempo no tratamento dessa matéria por parte do Executivo, de que este vem por seguidas vezes esquivando-se de dar uma regulamentação à matéria, mesmo tendo apreciado e vetado algumas propostas que o Congresso lhe enviou, algo que trataremos na seção a seguir.

\section{A decisão de não decidir}

A aprovação da Emenda n. 15/1996, exigindo a edição de disposições legais que objetivam assegurar a eficácia do $\S 4^{\circ}$ do art. 18 da Constituição, tem motivado a apresentação de várias proposições no Congresso Nacional, nenhuma delas transformada em lei até agora. 0 Brasil não conta, hoje, com regras de aplicação nacional nessa perspectiva e, portanto, não pode haver criação, incorporação, fusão e desmembramento de municípios no país, se o caso não estiver estritamente enquadrado no disposto no art. 96 do ADCT.

Dessas iniciativas, quatro processos chegaram a ser finalizados, com produção de texto legislativo enviado à sanção presidencial: Projeto de Lei (PL) n. 2.105/1999 ${ }^{9}$ e apenso; Projeto de Lei (Complementar) do Senado

\footnotetext{
${ }^{8}$ Pescaria Brava (SC) tem 9.416 habitantes; Balneário Rincão (SC), 11.136 habitantes; Pinto Bandeira (RS), 2.578 habitantes; e Paraíso das Águas (MS), 4.723 habitantes, segundo projeção do Instituto Brasileiro de Geografia e Estatística (IBGE, 2012). Mojuí dos Campos (PA) está na situação no mínimo curiosa de ter mais eleitores cadastrados do que habitantes, 16.867 contra 15.018 (CASTRO, 2013), o que imporá recontagem populacional.

${ }^{9}$ Número na Câmara dos Deputados, casa de origem. Havia um projeto de lei apenso. No Senado, Projeto de Lei da Câmara (PLC) n. 92/2002.
}

(PLS) n. 184/2002 ${ }^{10}$; Projeto de Lei (Complementar) do Senado (PLS) n. 98/2002 e apensos ${ }^{11}$; Projeto de Lei (Complementar) do Senado (PLS) n. 104/2014. Nos quatro processos, ocorreu veto à totalidade da proposta.

O PL n. 2.105/1999, de autoria do Deputado Valdemar Costa Neto (PL/SP), pretendia definir “[...] parâmetros mínimos para os Estudos de Viabilidade Municipal previstos no $§ 4^{\circ}$ - do art. 18 da Constituição Federal de 1988". O texto final do processo, um substitutivo construído ao longo do debate legislativo, foi integralmente vetado pelo Presidente da República, ao alegar inconstitucionalidade. A mensagem que comunicou o veto total (Brasil, 2003a) questiona que a interpretação conferida ao texto da Constituição admite a conclusão de que sejam necessárias duas leis, uma lei ordinária e uma lei complementar para tratar do mesmo dispositivo constitucional. Não apresenta, contudo, considerações de mérito quanto ao conteúdo da proposta encaminhada à sanção. 0 veto foi mantido pelo Congresso Nacional ${ }^{12}$.

O PLS n. 184/2002, de autoria do Senador Chico Sartori (PSDB/RO), vedava a tramitação de procedimentos para a criação, incorporação, fusão e desmembramento de municípios, a partir de dez meses da data prevista para a realização das eleições municipais até a posse dos prefeitos eleitos. Se já em curso, o procedimento ficaria sobrestado durante o referido período. A mensagem que comunicou o veto total (Brasil, 2003b) fala em inconstitucionalidade e contrariedade ao interesse público. Afirma que o texto aprovado pelo Legislativo não dispunha sobre a matéria com a precisão e a clareza necessárias. Defende que a lei complementar também tem de abranger os EVM. 0 veto foi mantido pelo Congresso Nacional.

O PLS n. 98/2002, de autoria do Senador Mozarildo Cavalcanti (PTB/RR), em sua versão final contempla tanto o período para criação, incorporação, fusão e desmembramento de municípios quanto o conteúdo dos EVM e outros aspectos relacionados ao tema. Trata-se de uma regulamentação completa do $§ 4^{\circ} \stackrel{\circ}{ }$ do art. 18 da

\footnotetext{
${ }^{10}$ Número no Senado Federal, casa de origem. Na Câmara, Projeto de Lei Complementar (PLP) n. 41/2003.

${ }^{11}$ Número no Senado Federal, casa de origem. Na Câmara, PLP n. $416 / 2008$.

${ }^{12}$ Muito raramente o Congresso Nacional derruba vetos do Presidente da República, qualquer que seja a área temática da proposição legislativa em foco.
} 
Constituição. Nas regras sobre os EVM, são contempladas exigências sobre a viabilidade econômico-financeira, político-administrativa e socioambiental e urbana, ou seja, não se trata de uma proposta direcionada simplesmente a "abrir a porteira" para a criação de novos municípios, mesmo que seu conteúdo porventura pudesse ser aperfeiçoado. Mais uma vez, veio o veto total. A mensagem presidencial (Brasil, 2013a) afirma que a aprovação da lei complementar viabilizaria a expansão expressiva do número de municípios no país, resultando em aumento de despesas e de pulverização na repartição do FPM.

O PLSn. $104 / 2014^{13}$, de autoria do Senador Mozarildo Cavalcanti e de outros parlamentares, reflete negociações em torno do texto final do processo de 2002. Segundo expresso no próprio avulso da matéria, o conteúdo da proposta advém de articulação entre Legislativo e Executivo. Essas negociações continuaram ao longo do processo e geraram substitutivo da Câmara dos Deputados, que, encaminhado à sanção presidencial, foi objeto de outro veto integral. Mesmo prevendo um EVM com conteúdo bastante amplo, o texto talvez não oferecesse parâmetros suficientemente objetivos para a avaliação desses estudos, o que poderia levar as decisões nesse campo a permanecer em seara mais política do que técnica. Mas não foi essa a motivação apresentada na mensagem presidencial (Brasil, 2014), ao voltar a falar na geração de despesas com a criação de novos municípios, além de citar dificuldades com a repartição do FPM.

Em suma, o governo federal, nos quatro casos relatados, decidiu que não decidiria sobre a regulamentação do $\S 4^{\circ}$ do art. 18 da Constituição. Com isso, inviabilizam-se rearranjos na divisão territorial brasileira na escala local, que envolvem não apenas a criação de novos municípios, mas também as iniciativas de incorporação e de fusão de municípios ${ }^{14}$. Essa situação não parece ter sustentabilidade técnica ou política, mesmo se considerado o médio prazo.

0 caminho alternativo adotado pelo Executivo federal tem sido reforçar a base normativa dos consórcios e

\footnotetext{
$\overline{13}$ Número no Senado, casa de origem. Na Câmara, ver PLP n. $397 / 2014$.

${ }^{14}$ A incorporação envolve a completa integração de um município a outro preexistente, perdendo o município integrado sua personalidade jurídica. Na fusão, por seu turno, há completa integração de dois ou mais municípios preexistentes, originando um novo município com personalidade jurídica própria.
}

impulsionar a adoção dessa ferramenta em diferentes áreas de políticas públicas. A entrada em vigor da Lei n.11.107 (Brasil, 2005), que viabilizou a autonomia jurídica dos consórcios públicos e a participação de União, estados, Distrito Federal (DF) e municípios em sua composição, realmente concretizou avanço de relevo (Linhares et al., 2012). Os consórcios, contudo, como nenhum outro instrumento de gestão pública, não podem ser encarados como uma panaceia. Eles não substituem os processos de criação, incorporação, fusão e desmembramento de municípios, mesmo que o Executivo federal entenda que sim.

\section{Formalização de regiões metropolitanas e outras aglomerações urbanas}

\section{O período anterior a 1988}

A Constituição de 1967/1969 estabelecia como prerrogativa exclusiva da União a institucionalização, mediante lei complementar federal, de regiões metropolitanas, “[...] constituídas por Municípios que, independentemente de sua vinculação administrativa, integrem a mesma comunidade socioeconômica, visando à realização de serviços de interesse comum" (art. 157, § 10). Assim, os requisitos eram que os municípios configurassem uma comunidade socioeconômica e que, por isso, a gestão integrada de determinados serviços de interesse comum fosse importante. Em princípio, a região metropolitana poderia contemplar municípios de mais de um estado, mas essa alternativa não chegou a ser concretizada.

Com base nessa previsão, aprovou-se a Lei Complementar n. 14 (Brasil, 1973), estabelecendo as regiões metropolitanas de São Paulo, Belo Horizonte, Porto Alegre, Recife, Salvador, Curitiba, Belém e Fortaleza. Nessa lei, também se definiu um modelo-padrão de governança metropolitana, imposto pelo governo federal: haveria em cada região metropolitana um conselho deliberativo, presidido pelo Governador do estado, e um conselho consultivo, criados por lei estadual. 0 conselho deliberativo contaria em sua composição, além do presidente, com cinco membros nomeados pelo Governador do estado, sendo um deles escolhido entre os nomes de lista tríplice organizada pelo prefeito da capital e outro mediante indicação dos demais municípios integrantes da região metropolitana. 0 conselho consultivo seria composto 
de um representante de cada município integrante da região metropolitana e funcionaria sob a direção do presidente do conselho deliberativo. Apesar de o texto da lei admitir genericamente outros processos de coordenação, fazia referência expressa à unificação da execução dos serviços comuns pela concessão do serviço a uma entidade estadual ou constituição de empresa de âmbito metropolitano ${ }^{15}$, condição para o repasse de recursos federais.

Definiam-se como de interesse metropolitano os seguintes serviços: planejamento integrado do desenvolvimento econômico e social, saneamento básico, uso do solo metropolitano, transportes e sistema viário, produção e distribuição de gás combustível canalizado e, na forma que viesse a dispor lei federal, aproveitamento dos recursos hídricos e controle da poluição ambiental. Além do mais, lei federal poderia incluir outros serviços. Vê-se que, além do modelo de gestão, impunha-se a lista de políticas públicas que deveriam funcionar em perspectiva metropolitana.

Seguindo o mesmo modelo, a Lei Complementar n. 20 (Brasil, 1974) instituiu a Região Metropolitana do Rio de Janeiro, ao mesmo tempo em que extinguiu o estado da Guanabara. Talvez como medida compensatória dessa extinção, a lei também criou fundo contábil, com recursos federais e estaduais, para o desenvolvimento da Região Metropolitana do Rio de Janeiro destinado a financiar os programas e os projetos prioritários para a região.

Esse padrão de gestão estabelecido de cima para baixo mostrou-se incapaz de enfrentar os problemas dessas regiões metropolitanas.

\section{O boom pós 1988: que vantagens traz a} formalização da região metropolitana?

A Constituição Federal atribui aos estados delimitar e formalizar regiões metropolitanas, em decisão do Legislador Constituinte que acompanhou a tendência de descentralização associada ao esforço de democratização do país. Rompeu-se com modelos e com práticas de centralização, às quais as regiões metropolitanas do regime militar estavam associadas (Souza, 2003).

Nos termos do art. 25, § 3ํㅡㄹ da Constituição (Brasil, 2015c), cabe à lei complementar estadual instituir

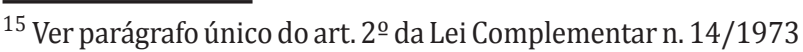
(Brasil, 1973).
}

regiões metropolitanas, aglomerações urbanas e microrregiões, constituídas por agrupamentos de municípios limítrofes, para integrar a organização, o planejamento e a execução de funções públicas de interesse comum.

Ao mesmo tempo, a consolidação dos municípios como entes federados autônomos pela Constituição (art. 18), por si só, tornou mais complexa a gestão das regiões metropolitanas. Não há mecanismos coercitivos para imposição das decisões dos entes de gestão metropolitana sobre os municípios partícipes. A governança metropolitana desenhada pela Constituição necessita ser pautada pela articulação política (Brasil, 2013b) ${ }^{16}$.

Uma leitura possível é que, não obstante a estadualização, as regiões metropolitanas continuam a ser associadas, principalmente pelas autoridades municipais, ao centralismo e ao autoritarismo do período militar. Há herança negativa derivada do fato de essa institucionalidade ter raízes na ditadura, em processo com elementos de dependência de trajetória (Souza, 2003). Outro aspecto a ser considerado é que a competição intermunicipal, por sediar atividades econômicas, via incentivos fiscais em esquemas não raramente predatórios, distancia os municípios da coordenação metropolitana. Souza (2003, p. 148-149) destaca que a ausência de estruturas políticas e administrativas nas regiões metropolitanas após 1988 " [...] transformou questões de governança urbana/metropolitana em questões de governança local, deixando os temas metropolitanos em um vazio político e administrativo". Com isso, na prática, não tem havido ação conjunta efetiva considerando-se a gestão metropolitana (Santos et al., 2013).

Apesar disso, nesse último pouco mais de um quarto de século, os estados formalizaram por leis complementares grande número de regiões metropolitanas. Não há consenso, contudo, sobre o número exato delas.

Em 2009, de acordo com um estudo do Observatório das Metrópoles (Ribeiro et al., 2009), existiam 26 áreas urbanas consideradas regiões metropolitanas.

\footnotetext{
${ }^{16}$ Esse quadro tende a ser pelo menos em parte alterado com a aplicação, a partir de março de 2015, da decisão do STF no âmbito da Ação Direta de Inconstitucionalidade (ADI) n. 1842 - RJ. A decisão, referente aos serviços de saneamento básico na Região Metropolitana do Rio de Janeiro, fala no caráter compulsório da integração metropolitana, mas, ao mesmo tempo, em autonomia municipal e titularidade compartilhada entre estado e municípios.
} 
O IBGE trabalhou no Censo 2010 com 36 regiões metropolitanas ${ }^{17}$. Somando-se a população delas com a das três Rides com características urbanas criadas pela União ${ }^{18}$, há 89.130 .667 habitantes, ou seja, $46,7 \%$ da população total do país, englobando zonas urbanas e rurais.

O Instituto de Pesquisa Econômica Aplicada (Ipea) menciona a existência de 51 regiões metropolitanas (Firkowski, 2013, p. 37), mas opta por estudar as $12^{19}$ que têm cidades-polo com influência em escala metropolitana, segundo o estudo Rede de Influência das Cidades (REGIC) (IBGE, 2008), em face do divórcio entre o processo socioespacial de formação de espaços metropolitanos e a metropolização institucional (Costa \& Tsukumo, 2013, p. 11). Em palavras mais simples, os estados têm definido mediante lei complementar estadual regiões metropolitanas que não possuem os requisitos técnicos para tanto, sobretudo pela cidade-polo não ter região de influência de uma metrópole.

Nos debates legislativos sobre o Estatuto da Metrópole, encontraram-se pouco mais de 60 regiões metropolitanas formalizadas no país (Câmara dos Deputados, 2013), as quais, juntas, ultrapassam $50 \%$ da população brasileira e com características bastante distintas.

Da megalópole de São Paulo, cuja região metropolitana somava em 2010 perto de 20 milhões de habitantes, chega-se a casos como as regiões metropolitanas de Lajes (SC) e do Sudoeste Maranhense (MA), com cerca de 350 mil habitantes cada, ou casos extremos como a Região Metropolitana do Sul de Roraima, com três municípios que totalizam pouco mais de 20 mil habitantes (IBGE, 2011).

Deve-se comentar também que os estados têm deixado de lado a opção de delimitar aglomerações urbanas não qualificadas como regiões metropolitanas. Há apenas cinco casos no país: Jundiaí (SP), Piracicaba (SP), Litoral Norte (RS), Nordeste do Rio Grande do Sul (região de Caxias do Sul) e Aglomeração Urbana Central (região de São Carlos e de Araraquara, em São Paulo).

\footnotetext{
${ }^{17}$ Ver Tabela 5.1.1 nos resultados do Censo 2010 (IBGE, 2014).

${ }^{18}$ Ride-DF, Ride Juazeiro- Petrolina e Ride Teresina-Timon (Grande Teresina).

${ }^{19}$ Entre estas 12 priorizadas pelo Ipea, inclui-se a Ride do Distrito Federal (DF) e Entorno, autorizada pela Lei Complementar n. 94/1998 e criada pelo Decreto n. 2.710/1998.
}

Aglomeração urbana é um gênero do qual a região metropolitana é uma espécie. Na aplicação prática do art. 25, § 3o, da Constituição Federal (Brasil, 2015c), aglomerações urbanas que não têm cunho metropolitano, e mesmo determinadas microrregiões, têm recebido legalmente o rótulo de região metropolitana.

Quais as razões desse boom de regiões metropolitanas aprovadas mediante lei complementar estadual?

Não há, como no caso da criação de municípios, transferências obrigatórias de recursos federais a partir da criação de uma região metropolitana. A pressão pela criação de um município, em regra, terá componentes políticos fortes, mas se robustece pela garantia da autonomia como ente federado, bem como da obtenção de um volume mínimo de recursos federais, especialmente via FPM, além das transferências estaduais. Na criação das regiões metropolitanas, contudo, a explicação do seu boom de emancipações não se evidencia tão claramente quanto no que se refere à criação de municípios. Isso suscita elementos explicativos que podem estar ligados a particularidades políticas estaduais capazes de explicação mais clara acerca dessa questão, o que traz um espaço interessante para futuras pesquisas com estudos de casos específicos ou comparados.

Como benefícios diretos da formalização de uma região metropolitana, aponta-se, por exemplo, o fato de as ligações telefônicas entre os municípios integrantes tenderem a ser consideradas locais. As normas de Agência Nacional de Telecomunicações (Anatel) não preveem a transformação imediata em tarifa $\operatorname{local}^{20}$, mas têm sido feitos ajustes frequentes nas áreas de tarifação com essa perspectiva.

Outro ponto levantado nos debates sobre o tema são regras trabalhistas que padronizam salários da mesma empresa no âmbito de uma mesma região metropolitana. De fato, enunciado do Tribunal Superior do Trabalho (TST) considera mesma localidade, para fins de equiparação salarial, também municípios distintos que pertençam à mesma região metropolitana ${ }^{21}$.

Esses benefícios não são suficientes, todavia, para explicar as mais de 60 regiões metropolitanas criadas pelos estados após 1988.

\footnotetext{
${ }^{20}$ Ver Resolução n. 262/2001 e Resolução n. 560/2011 da Anatel.

${ }^{21}$ Ver Enunciado n. 6 do TST, com redação atualizada (DJi, 2014).
} 
Mais recentemente, alguns programas do governo federal, na prática, têm priorizado regiões metropolitanas, como o Programa Minha Casa, Minha Vida (PMCMV), mas não há base legal para essa prioridade. No PMCMV, a destinação de recursos para as regiões metropolitanas parece, em princípio, decorrer da própria conformação do déficit habitacional.

De modo geral, percebe-se, nos últimos anos, que o discurso metropolitano ressurge aos poucos na esfera federal de governo. A recente sanção da Lei n. 13.089/2015 (Estatuto da Metrópole) corrobora isso. No âmbito do Executivo federal, curiosamente, a retomada do tema tem-se vinculado mais à Secretaria de Relações Institucionais (SRI) da Presidência da República, que responde pela interlocução da Presidência com estados, municípios e o Distrito Federal (DF) ${ }^{22}$, do que ao Ministério das Cidades $^{23}$.

\section{Estatuto da metrópole}

Durante o processo que gerou a Lei n. 10.257/2001 (Estatuto da Cidade), chegou a ser redigido capítulo com normas gerais sobre as regiões metropolitanas, o que se justificaria plenamente em face da relação entre essas regiões e a dinâmica da urbanização no país. Os dispositivos com esse conteúdo, contudo, foram considerados inconstitucionais pela comissão permanente da Câmara dos Deputados, que faz a análise de constitucionalidade e de juridicidade ${ }^{24}$, em face de a Constituição ter remetido esse tema ao campo decisório dos estados.

Na verdade, o período imediatamente após 1988 marcou-se pelo reforço do papel dos municípios em diferentes áreas de políticas públicas, como sinônimo de busca de contato direto com os beneficiários das ações governamentais e, assim, de democratização (Souza, 1996).

\footnotetext{
${ }^{22}$ Ver art. $2^{\circ}$-A da Lei n. 10.683/2003, acrescido pela Lei n. $11.204 / 2005$

${ }^{23}$ O Ministério das Cidades não mantém programas direcionados especificamente às regiões metropolitanas. Mencione-se que a SRI foi o órgão consultado para os vetos ao Estatuto da Metrópole, juntamente com os Ministérios da Fazenda e do Planejamento, Orçamento e Gestão (Brasil, 2015b).

${ }^{24}$ Ver processo do Projeto de Lei n. 5.788/1990 e apensos na Câmara dos Deputados e do Projeto de Lei do Senado (PLS) n. 181/1989 no Senado Federal.
}

O Estatuto da Cidade sofre repercussões disso e se estrutura, basicamente, como uma caixa de ferramentas de política urbana colocada à disposição das municipalidades (Campos, 2010). Essa leitura essencialmente municipalista também marcou a organização do Ministério das Cidades em 2003, que não possui até hoje uma coordenação dedicada à questão metropolitana.

Em 2004, foi apresentado na Câmara dos Deputados, pelo Deputado Walter Feldman (PSDB/SP) ${ }^{25}$, o PL n. 3.460/2004, autodenominado Estatuto da Metrópole. A proposta inicial tinha o objetivo ambicioso de instituir a Política Nacional de Planejamento Regional Urbano e criar o Sistema Nacional de Planejamento e Informações Regionais Urbanas. Vale dizer que esse recorte é frágil, uma vez que o planejamento regional envolve inúmeros temas que vão além da política urbana. $O$ texto tinha também um viés paulistano, com requisitos para a criação de regiões metropolitanas que excluiriam outros casos, além da Região Metropolitana de São Paulo. Por esses problemas, o processo permaneceu lento por anos.

A partir de 2012, esse quadro foi revertido, com a organização de debates voltados à construção do futuro Estatuto da Metrópole, que contaram com a participação de muitos técnicos da área e representantes de organizações governamentais e não governamentais. No final de 2013, a Câmara aprovou um substitutivo ao texto inicial do PL n. 3.460/2004, que foi aprovado pelo Senado Federal, sem alterações, em dezembro de 2014 e remetido à sanção, gerando a Lei n. 13.089/2015. É um texto legal enxuto, que complementa o Estatuto da Cidade no que se refere à gestão metropolitana. A nova lei, em síntese (Brasil, 2015a):

- fixa aspectos mínimos a serem definidos pelas leis complementares estaduais que instituírem regiões metropolitanas e aglomerações urbanas;

- estabelece princípios a serem respeitados na governança federativa, entre os quais se destacam a prevalência do interesse comum sobre o local e o compartilhamento de responsabilidades para a promoção do desenvolvimento urbano integrado;

- define diretrizes a serem observadas na governança federativa, entre as quais se

\footnotetext{
${ }^{25}$ Atualmente ligado à Rede Sustentabilidade.
} 
destacam: implantação de processo permanente e compartilhado de planejamento e de tomada de decisão quanto ao desenvolvimento urbano e às políticas setoriais afetas às funções públicas de interesse comum; estabelecimento de meios compartilhados de organização administrativa das funções públicas de interesse comum; execução compartilhada das funções públicas de interesse comum, mediante rateio de custos previamente pactuado no âmbito da estrutura de governança federativa;

- exige a elaboração de plano de desenvolvimento urbano integrado de região metropolitana ou aglomeração urbana, independentemente do plano diretor municipal, como instrumento de governança federativa;

- estabelece condições para o apoio da União às iniciativas dos estados e municípios voltadas à governança federativa em regiões metropolitanas e aglomerações urbanas.

A relatoria da comissão especial formada por um parlamentar da base, o saudoso Deputado Zezéu Ribeiro (PT/BA), especialista no tema, parece ter contribuído para o consenso em relação a essa lei.

Cabe registrar que a Lei n. 13.089/2015 traz disposições que objetivam frear a formalização de regiões metropolitanas que não tenham a devida sustentação técnica. $\mathrm{O}$ conceito de metrópole (inciso V do art. $2^{\circ}$ da lei) prevê que ela tenha influência nacional ou sobre uma região que configure, no mínimo, a área de influência de uma capital regional, conforme os critérios adotados pelo IBGE. A região metropolitana necessita configurar uma metrópole (inciso VII do art. $2^{\circ}$ ) e o repasse de recursos federais passará a observar essa determinação ( $\left(1^{\circ}\right.$ o do art. 14). (Brasil, 2015a).

Foram vetados quatro dispositivos (Brasil, 2015b). 0 primeiro deles era o que pretendia estender as disposições da lei, no que coubesse, às cidades que, apesar de se situarem no território de apenas um município,

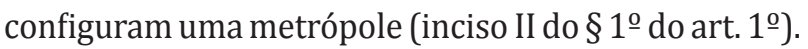
0 veto do dispositivo, que teria aplicação especialmente nas regras para o repasse de recursos da União, não chega a ter grande implicação, uma vez que as metrópoles brasileiras, em regra, envolvem um grupo de municípios. Há de registrar, contudo, que a justificativa do veto (Brasil, 2015b), que alega a inconstitucionalidade do dispositivo, não subsiste, uma vez que metrópole e região metropolitana são conceitos distintos (ver incisos V e VII do art. $2^{2}$ da Lei n. 13.089/2015).

0 segundo veto refere-se ao artigo que admitia que o Distrito Federal (DF) integrasse uma região metropolitana ou aglomeração urbana (art. 19 da lei). Parece estranha a afirmação de inconstitucionalidade em razão de o Distrito Federal (DF) não ser composto por municípios (art. 32, caput, da Constituição), uma vez que a ele são atribuídas as competências legislativas de estados e municípios (art. 32, §1ํㅡ, da Constituição) e há possibilidade de ser criada região metropolitana interestadual (art. 4º da Lei n. 13.089/2015). Além disso, a Ride do Distrito Federal (DF) e Entorno, em sua essência, é uma região metropolitana interestadual. Manter a sua institucionalidade implica uma concentração de poder no governo federal incompatível com a natureza da gestão urbana.

0 terceiro e quarto vetos (arts. 17 e 18 da lei) referem-se à criação do Fundo Nacional de Desenvolvimento Urbano Integrado (FNDUI). A alegação foi de que "a criação de fundos cristaliza a vinculação a finalidades específicas, em detrimento da dinâmica intertemporal de prioridades políticas" (Brasil, 2015b). Há críticas dos urbanistas e do próprio relator da matéria na Câmara quanto a esses vetos (CAU/BR, 2015).

\section{Considerações finais}

As duas narrativas analíticas trazidas por este trabalho, envolvendo a base institucional federal relativa à criação de municípios e à formalização de regiões metropolitanas e de outras aglomerações urbanas, mostram que o governo federal tem demonstrado dificuldade de cumprir sua parte no enfrentamento do desafio da governança complexa, que é decorrente de nosso federalismo singular em três níveis.

No lugar de apoiar e de gerir de forma coordenada, não raramente, tem havido omissão com temas ignorados há anos (a exemplo da desatenção do Ministério das Cidades para as regiões metropolitanas e outras aglomerações urbanas) e, no sentido oposto, imposições do Leviatã que desconsideram a federação (a exemplo da decisão de não decidir sobre as regras nacionais referentes à criação de novos municípios). Há algumas novidades relevantes nos temas aqui estudados, especificamente a transformação da proposta do Estatuto da Metrópole na Lei n. 13.089/2015. 
Se a recente sanção do Estatuto da Metrópole traz expectativas positivas, os vetos realizados podem ser objeto de críticas, como já colocado. Em especial, a não aceitação da proposta de criação do FNDUI, mesmo que fundamentada em uma posição mais ampla contra a criação de fundos, evidencia, pelo menos em alguma medida, a não priorização do tema no âmbito do governo federal.

Por sua vez, é importante colocar em relevo que as regras sobre criação de municípios não podem permanecer uma lacuna eterna, pois não há sustentação política - e mesmo técnica - para a situação atual nesse tema. 0 número exacerbado de municípios deve ser controlado por regras, não pela ausência delas.

\section{Referências}

Abrucio, F. L. (2005). A coordenação federativa no Brasil: a experiência do período FHC e os desafios do governo Lula. Revista de Sociologia e Política, (24), 41-67.

Almeida, M. H. T. (2005). Recentralizando a federação? Revista de Sociologia e Política, (24), 29-40. http://dx.doi. org/10.1590/S0104-44782005000100004

Araújo, S. M. V. G., \& Lorenzetti, M. S. B. (2008). A Constituição Federal de 1988 e a criação de novos municípios e regiões metropolitanas. In J. C. Araújo, J. S. Pereira Jr., L. S. Pereira, \& R. J. P. Rodrigues (Orgs.), Ensaios sobre impactos da Constituição Federal de 1988 na sociedade brasileira (Vol. 2, p. 639-657). Brasília: Câmara dos Deputados.

Arretche, M. T. S. (2000). Estado Federativo e Políticas Sociais: determinantes da descentralização. Rio de Janeiro: Revan; São Paulo: Fapesp.

Arretche, M. T. S. (2012). State effectiveness in contemporary Brazil. In Proceedings from XLII LASA Forum (p. 15-17). Pittsburgh: LASA.

Barzelay, M., \& Cortazar-Velarde, J. C. (2004). Una guía práctica para la elaboración de estudios de caso sobre buenas prácticas en gerencia social. Washington: Banco Interamericano de Desarrollo. Recuperado em 10 de dezembro de 2014, de http://preval.org/es/content/unagu\%C3\%AD-pr\%C3\%A1ctica-para-la-elaboraci\%C3\%B3nde-estudios-de-caso-sobre-buenas-pr\%C3\%A1cticas-engerencia

Brasil. (1966, 31 de outubro). Lei n. 5.172, de 25 de outubro de 1966. Dispõe sobre o Sistema Tributário Nacional e institui normas gerais de direito tributário aplicáveis à
União, Estados e Municípios. Brasília: Diário Oficial [da] República Federativa do Brasil.

Brasil. (1967, 24 de janeiro). Constituição da República Federativa do Brasil. Redação dada pela Emenda Constitucional n. 1, de 17 de outubro de 1969. Brasília: Diário Oficial [da] República Federativa do Brasil. Recuperado em 30 de janeiro de 2015, de http://www.planalto.gov.br/ccivil_03/ Constituicao/Constituicao67.htm

Brasil. (1973, 11 de junho). Lei Complementar n. 14, de 8 de junho de 1973. Estabelece as regiões metropolitanas de São Paulo, Belo Horizonte, Porto Alegre, Recife, Salvador, Curitiba, Belém e Fortaleza. Brasília: Diário Oficial [da] República Federativa do Brasil.

Brasil. (1974, 1 de julho). Lei Complementar n. 20, de $1^{\circ}$ de julho de 1974. Dispõe sobre a criação de Estados e Territórios. Brasília: Diário Oficial [da] República Federativa do Brasil.

Brasil. (1981, 29 de agosto). Decreto-Lei n. 1.881, de 27 de agosto de 1981. Altera a Lei $n^{\circ}-5.172$, de 25 de outubro de 1966, cria a Reserva do Fundo de Participação dos Municípios - FPM a dá outras providências. Brasília: Diário Oficial [da] República Federativa do Brasil.

Brasil. (1988, 5 de outubro). Constituição da República Federativa do Brasil. Brasília: Diário Oficial [da] República Federativa do Brasil.

Brasil. (1996, 13 de setembro). Emenda constitucional $n$. 15, de 12 de setembro de 1996. Dá nova redação ao $\S 4^{\circ}$ do art. 18 da Constituição Federal. Brasília: Diário Oficial [da] República Federativa do Brasil.

Brasil. (2001, 17 de julho). Lei n. 10.257, de 10 de julho de 2001. Regulamenta os arts. 182 e 183 da Constituição Federal, estabelece diretrizes gerais da política urbana e dá outras providências. Brasília: Diário Oficial [da] República Federativa do Brasil.

Brasil. Presidência da República. (2003a, 6 de janeiro). Mensagem ao Congresso Nacional n. 4, de 6 de janeiro de 2003. Brasília: Diário Oficial [da] República Federativa do Brasil.

Brasil. Presidência da República. (2003b, 19 de agosto). Mensagem ao Congresso Nacional n. 70, de 19 de agosto de 2003. Brasília: Diário Oficial [da] República Federativa do Brasil.

Brasil. (2005, 7 de abril). Lei n. 11.107, de 6 de abril de 2005. Dispõe sobre normas gerais de contratação de consórcios públicos e dá outras providências. Brasília: Diário Oficial [da] República Federativa do Brasil. 
Brasil. (2008, 18 de dezembro). Emenda constitucional $n$. 57, de 18 de dezembro de 2008. Acrescenta artigo ao Ato das Disposições Constitucionais Transitórias para convalidar os atos de criação, fusão, incorporação e desmembramento de Municípios. Brasília: Diário Oficial [da] República Federativa do Brasil.

Brasil. Presidência da República. (2013a, 12 de novembro). Mensagem ao Congresso Nacional n. 131, de 12 de novembro de 2013. Brasília: Diário Oficial [da] República Federativa do Brasil.

Brasil. Supremo Tribunal Federal. (2013b). Ação direta de inconstitucionalidade 1.842 Rio de Janeiro. Brasília; 2013. Recuperado em 10 de janeiro de 2015, de http://redir.stf.jus. $\mathrm{br} /$ paginadorpub/paginador.jsp?docTP=AC\&docID=630026

Brasil. Presidência da República. (2014, 29 de agosto). Mensagem ao Congresso Nacional n. 250, de 29 de agosto de 2014. Brasília: Diário Oficial [da] República Federativa do Brasil.

Brasil. (2015a, 13 de janeiro). Lei n. 13.089, de 12 de janeiro de 2015. Institui o Estatuto da Metrópole, altera a Lei $n^{\circ}$ 10.257, de 10 de julho de 2001, e dá outras providências. Brasília: Diário Oficial [da] República Federativa do Brasil.

Brasil. Presidência da República. (2015b, 13 de janeiro). Mensagem n. 13, de 12 de janeiro de 2015. Brasília: Diário Oficial [da] República Federativa do Brasil.

Brasil. Câmara dos Deputados. (2015c). Constituição da República Federativa do Brasil (46. ed.). Brasília: Edições Câmara.

Câmara dos Deputados. (2013). Reuniões técnicas da Comissão Especial do Estatuto da Metrópole. Brasília. Arquivos em áudio.

Campos, J. R. B. (2010). Estatuto da Cidade: a construção de uma lei. In C. S. Carvalho, \& A. C. Rossbach (Orgs.), $O$ Estatuto da Cidade: comentado. Brasília: Ministério das Cidades; São Paulo: Aliança das Cidades.

Castro, J. (2013, 19 de janeiro). Com 5 novos municípios, Brasil agora tem 5.570 cidades. São Paulo: 0 Globo. Recuperado em 30 de abril de 2014, de http://oglobo. globo.com/pais/com-5-novos-municipios-brasil-agoratem-5570-cidades-7235803

Conselho de Arquitetura e Urbanismo do Brasil - CAU/BR. (2015). Dilma sanciona Estatuto da Metrópole com veto a fundo de desenvolvimento. Brasília. Recuperado em 10 de janeiro de 2015, de http://www.caubr.gov.br/?p=37513
Costa, M. A., \& Tsukumo, T. L. (2013). 40 anos de regiões metropolitanas no Brasil. Brasília: Ipea.

DJi. Recuperado em 10 de abril de 2014, de http://www. dji.com.br/normas_inferiores/enunciado_tst/tst_0006.htm.

Fernandes, M. E. (2010). História de vida: dos desafios de sua utilização. Revista Hospitalidade, 7(1), 15-31.

Fernandes, M. S. (2009). Subcomissão dos municípios e regiões. In A. L. Backes, D. B. Azevedo, \& J. C. Araújo (Orgs.), Audiências Públicas na Assembléia Nacional Constituinte: a sociedade na tribuna (p. 156-174). Brasília: Câmara dos Deputados.

Firkowski, O. L. C. F. (2013). Metrópoles e regiões metropolitanas no Brasil: conciliação ou divórcio? In B. A. Furtado, C. Krause, \& K. C. B. França (Orgs.), Território metropolitano, políticas municipais: por soluções conjuntas de problemas urbanos no âmbito metropolitano (p. 21-51). Brasília: Ipea.

Instituto Brasileiro de Geografia e Estatística - IBGE. (2008). Rede de influência das cidades 2007. Rio de Janeiro.

Instituto Brasileiro de Geografia e Estatística - IBGE. (2011). Evolução da divisão territorial do Brasil 1872-2010. Rio de Janeiro.

Instituto Brasileiro de Geografia e Estatística - IBGE. (2012). Estimativas populacionais para os municípios brasileiros em 01.07.2012. Rio de Janeiro. Recuperado em 30 de janeiro de 2015, de http://www.ibge.gov.br/home/estatistica/ populacao/estimativa2012/default.shtm

Instituto Brasileiro de Geografia e Estatística - IBGE. (2014). Caracteristicas da população e dos domicílios: resultados do universo. Rio de Janeiro. Recuperado em 10 de maio de 2014, de http://www.ibge.gov.br/home/estatistica/ populacao/censo2010/caracteristicas_da_populacao/ caracteristicas_da_populacao_tab_rm_zip_xls.shtm

Lijphart, A. (2003). Modelos de democracia. Rio de Janeiro: Civilização Brasileira.

Linhares, P. T. F., Cunha, A. S., \& Ferreira, A. P. L. (2012). Cooperação federativa: a formação de consórcios entre entes públicos no Brasil. In P. T. F. Linhares, C. C. Mendes, \& A. Lassance (Orgs.), Federalismo à brasileira: questões para discussão. Brasília: Ipea.

Monteiro, A. M., No. (2013). Governos estaduais no federalismo brasileiro: capacidades e limitações no cenário atual (Textos para Discussão, Vol. 1894). Brasília: Ipea. 
North, D. (1993). Instituciones, cambio institucional y desempeño económico. Cidade do México: Fondo de Cultura Económica.

Pierson, P. (2004). Politics in time: history, institutions, and social analysis. Princeton: Princeton University Press.

Ribeiro, L. C. Q., Moura, R., Branco, M. L. C., Deschamps, M., \& Delgado, P. R. (2009). Hierarquização e identificação dos espaços urbanos (Conjuntura Urbana, Vol. 1). Rio de Janeiro: Letra Capital, Observatório das Metrópoles.

Santos, A. M. (2013). Topografia do Brasil profundo: votos, cargos e alinhamentos nos municípios brasileiros. Opinião Pública, 19(1), 1-20. http://dx.doi.org/10.1590/ S0104-62762013000100001

Santos, D. F., Fernandes, A. S. A., \& Teixeira, M. A. C. (2013). As Regiões Metropolitanas no Brasil e o problema Institucional de Cooperação: a trajetória das Regiões Metropolitanas de Natal e Aracaju. Cadernos EBAPE.BR (FGV), 11(3), 368-382.
Souza, C. (1996). Reinventando o poder local: limites e possibilidades do federalismo e da descentralização. São Paulo em Perspectiva, 10(3), 103-112. Recuperado em 10 de dezembro de 2014, de http://produtos.seade.gov.br/ produtos/spp/v10n03/v10n03_13.pdf

Souza, C. (2003). Regiões metropolitanas: condicionantes do regime político. Lua Nova, 59, 137-158. Recuperado em 11 de março de 2015, de http://www.scielo.br/pdf/ $\ln /$ n59/a07n59.pdf

Tomio, F. R. L. (2002). A criação de municípios após a Constituição de 1988. Revista Brasileira de Ciências Sociais, 17(48), 61-90. http://dx.doi.org/10.1590/ S0102-69092002000100006

Recebido: Fev. 01, 2015

Aprovado: Mar. 12, 2015 